\title{
Male description of the phytotelma-dwelling species Polypedilum parthenogeneticum (Chironomidae: Chironominae)
}

\author{
Mariano Donato ${ }^{1}$, Lara Baccaro ${ }^{2}$ and Augusto Siri ${ }^{3}$ \\ Instituto de Limnología 'Dr Raúl A. Ringuelet'(ILPLA), Universidad Nacional de La Plata - Consejo \\ Nacional de Investigaciones Cientificas y Técnicas, CCT La Plata, Boulevard 120 and 62, CC 712 (1900) \\ La Plata, Buenos Aires, Argentina.E-mails: ${ }^{1}$ marianodonato@ilpla.edu.ar, ${ }^{2}$ laritabaccaro@gmail.com, \\ 3augusto@ilpla.edu.ar
}

\begin{abstract}
The male of the phytotelma-dwelling species Polypedilum parthenogeneticum is described from Eryngium L. (Apiaceae) (Corrientes province, Argentina) and is included within the subgenus Polypedilum. The pupal diagnosis is emended, its geographic distribution is updated, and their taxonomic relationships with other Neotropical species of Polypedilum are discussed.
\end{abstract}

\section{Introduction}

The genus Polypedilum Kieffer, 1913 occurs in all zoogeographical regions except Antarctica (Vårdal et al. 2002). The larvae of this genus are found in sediments of standing and flowing waters, with a few species mining wood or grazing on epilithic surfaces (Cranston et al. 1989; Vårdal et al. 2002). This genus is quite diverse, with more than 500 species worldwide and about 70 belong to the Neotropical region. The taxonomic classifications and the subgeneric delimitation of Polypedilum have been problematic and were treated in several studies (Sæther et al. 2010; Cranston et al. 2016; Yamamoto and Yamamoto 2016; Shimabukuro et al. 2019),

The species Polypedilum parthenogeneticum was described by Donato \& Paggi (2008) based on reared material collected from the leaf axils of Eryngium L. (Apiaceae). All the specimens obtained were females and the parthenogenesis was confirmed in the laboratory, being the eclosion one day after the oviposition. New specimens of $P$. parthenogeneticum collected from the leaf axils of Eryngium sp. were reared in the laboratory and a male was obtained for the first time. Therefore, the aims of this study are to describe the male of $P$. parthenogeneticum and to provide new information on its geographic distribution, as well as to emend the pupal diagnosis of this species.

\section{Material and methods}

Microscope slides were prepared by clearing the specimen with $10 \% \mathrm{KOH}$; neutralization with glacial acetic acid; followed by a dehydration series of $80 \%, 96 \%$ and $100 \%$ ethanol and mounting in Canada Balsam. Morphological terminology and measurement standards follow Sæther (1980) and Bidawid-Kafka $\&$ Fittkau (1995); the values are rounded off to the nearest $5 \mu \mathrm{m}$ unless otherwise stated; measurements are given in $\mu \mathrm{m}$ (except when otherwise stated) as ranges. The specimens studied are deposited in the collection of the Instituto de Limnología "Dr. Raul A. Ringuelet”, Argentina (ILPLA).

\section{Taxonomy}

The subgenus Polypedilum defined by Sæther et al. (2010) is characterized for the lack of frontal tubercles; wing membrane without macrotrichia; $\mathrm{R}_{2+3}$ usually well separated from $\mathrm{R}_{1}$; superior volsella with a long projection, usually with lateral midbasal to subapical strong setae; and the anal point is never trifid or with lateral shoulders. As Cranston et al. 2016 considered Tripedilum as junior synonym of Polypedilum s. str., the absence of frontal tubercles and the presence of outer setae in the digitiform projection of superior volsella become inconsistent to define Polypedilum s. str. because those characters are diagnostic for Tripedilum as it was stated by Sæther et al. (2010) (see also Yamamoto and Yamamoto (2016) for further discussion). We consider the inclusion of P. parthenogeneticum in the subgenus Polypedilum by a combination of characters such as bare wing membrane, long digitiform projection of superior volsella and anal point not trifid, following Shimabukuro et al. (2019). The inclusion is also supported since the larval and pupal stages of $P$. parthenogeneticum belong to Polypedilum s. str. Taxonomic relationships of those stages together with the female are discussed in Donato and Paggi (2008). 


\section{Polypedilum (Polypedilum) parthenogeneticum Donato \& Paggi, 2008}

(Fig. 1)

Polypedilum parthenogeneticum Donato and Paggi 2008: 52.

Polypedilum (Polypedilum) parthenogeneticum, new combination.

Material examined. ARGENTINA: 1 male with pupal exuviae, Corrientes, Riachuelo, 27.5452754 $\mathrm{S}$, 58.7159499 ${ }^{\circ}$ W, 31.xii.2018, pipette phytotelmata in Eryngium L. (Apiaceae), L. Baccaro (ILPLA).

\section{Male description}

Total length $2.03 \mathrm{~mm}$; wing length $1.5 \mathrm{~mm}$. Total length/wing length 1.35 . Wing length/length of profemur 1.97.

Head. AR 1.24. Ultimate flagellomere 128 long. Temporal setae 13. Clypeus with 22 setae. Tentorium 117 long; 27 wide. Length of palp segments: 29;31;68; 87; 126. Third palpomere with 3 lanceolate sensilla clavata in small pit; longest 19 long.

Thorax. Dorsocentrals 11, with 3 on humeral area; acrostichals 7; prealars 3; antepronotals 1. Scutellum with 8 setae.

Wing (Fig. 1A). VR 1.15. Brachiolum with 1 seta. $\mathrm{R}$ with $18 ; \mathrm{R}_{1}$ with $9 ; \mathrm{R}_{4+5}$ with 21 ; remaining veins bare. Squama with 3 setae. Lengths and proportions of legs in Table 1.

Legs. Scale of fore tibia: 45. Spur of middle tibia: 16 and 56; of hind tibia: 26 and 70. Width at apex of fore tibia 50; of middle tibia 49; of hind tibia 54. Lengths and proportions of legs in Table 1.

Hypopygium (Fig. 1B, C). Tergite IX with 14 medial setae. Phalapodeme length: 76. Transverse sternapodeme length: 49. Superior volsella 74 long, lateral seta lacking, basal portion of superior volsella with microtrichia and 4 inner setae. Inferior volsella slender 120 long, with 11 setae arranged in two rows. Gonocoxite length: 128 . Gonostyle length: $159 . \mathrm{HR}=0.81 . \mathrm{HV}=1.28$.

Table 1. Lengths (in $\mu \mathrm{m}$ ) and proportions of legs of the male of Polypedilum (Polypedilum) parthenogeneticum Donato and Paggi $(\mathrm{n}=1)$. Abbreviations: Femur (fe); Tibia (ti); Tarsomeres 1-5 $\left(\mathrm{ta}_{1-5}\right)$; Leg Ratio (LR), ratio of metatarsus to tibia; «Beinverhältnisse» (BV), combined length of femur, tibia, and basitarsus divided by combined length of tarsomeres 2-5; «Schenkel-Scheine-verhältnis» (SV), ratio of femur plus tibia to metatarsus.

\begin{tabular}{ccccccccccc}
\hline & $\mathrm{fe}$ & $\mathrm{Ti}$ & $\mathrm{ta}_{1}$ & $\mathrm{ta}_{2}$ & $\mathrm{ta}_{3}$ & $\mathrm{ta}_{4}$ & $\mathrm{ta}_{5}$ & $\mathrm{LR}$ & $\mathrm{BV}$ & $\mathrm{SV}$ \\
\hline $\mathrm{P}_{1}$ & 763 & 474 & 886 & 577 & 392 & 289 & 144 & 1.87 & 1.51 & 1.40 \\
$\mathrm{P}_{2}$ & 804 & 660 & 536 & 227 & 165 & 103 & 82 & 0.81 & 3.46 & 2.73 \\
$\mathrm{P}_{3}$ & 927 & 660 & 598 & 309 & 289 & 165 & 103 & 0.91 & 2.52 & 2.66 \\
\hline
\end{tabular}

\section{Remarks}

The larva and pupa of this specimen fits in the original description, except that the branches of the thoracic horn present fine spinules in its tegument. This feature was corroborated also in the females previously described, and therefore the emendation of the pupal diagnosis of $P$. parthenogeneticum is established.

\section{Geographic distribution}

Through the present study, the distribution of the P. parthenogeneticum extends northward (about $800 \mathrm{~km}$ north to the type locality), with the new record located in Argentina in the Chacoan province of the biogeographic scheme of Cabrera and Willink (1973). Because of the notorious absence of male specimens on previous studies, it is possible that $P$. parthenogeneticum presents geographical parthenogenesis such that bisexual and parthenogenetic forms of the same species differ on their distributions (Vandel 1928).

\section{Discussion}

The male of $P$. parthenogeneticum most closely resembles $P$. (P.) solimoes Bidawid-Kafka (couplet 45, Bidawid-Kafka, 1996), but differs from this species by the possession of anal tergal bands type D; the superior volsella more curved, with 4 inner setae, lateral seta absent, and lower AR and LR ${ }_{1}$, The male of 

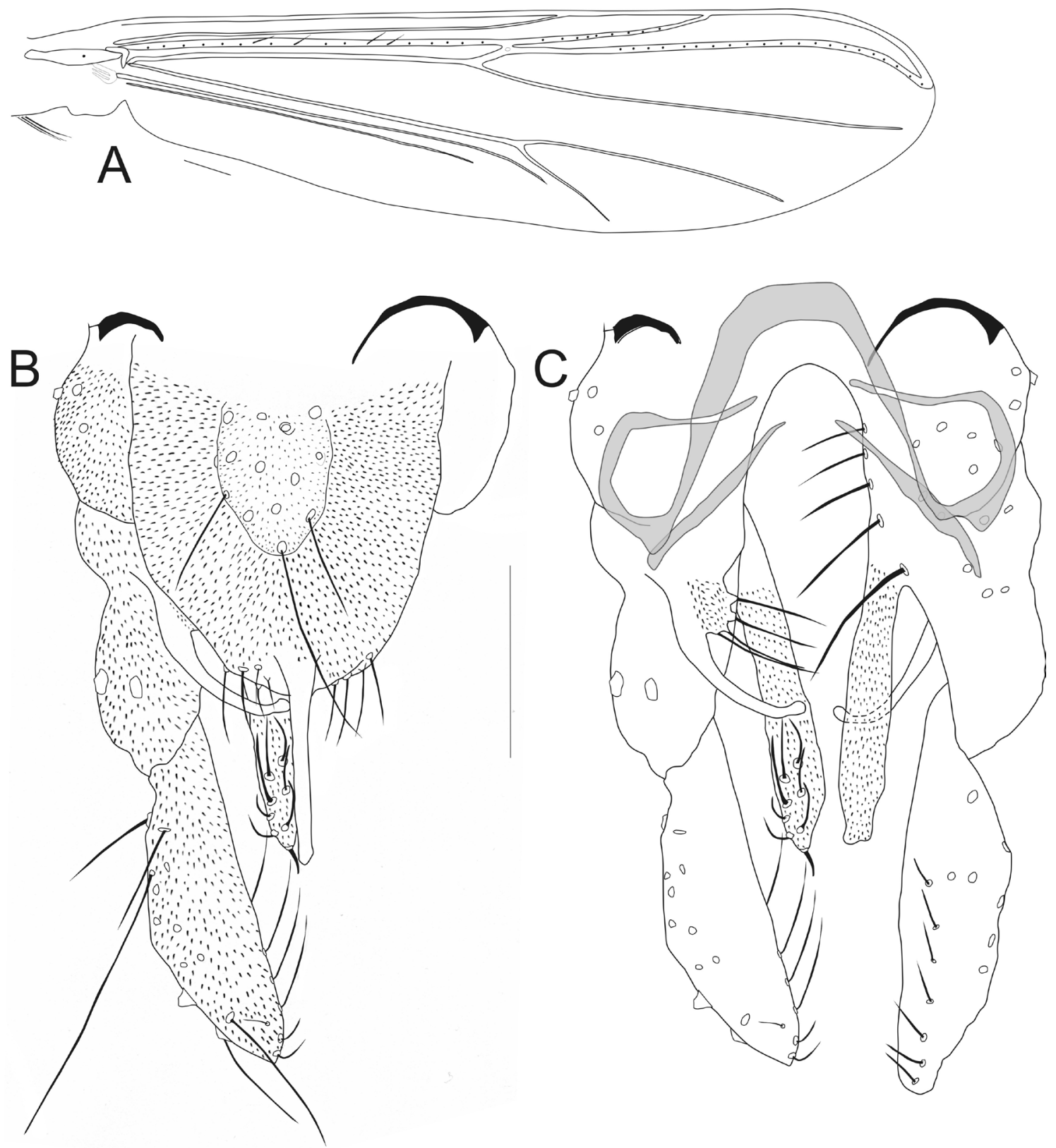

Figure 1. Polypedilum (Polypedilum) parthenogeneticum Donato and Paggi: A, wing; B, hypopygium, dorsal view; $\mathrm{C}$, hypopygium with anal point and tergite IX removed, dorsal aspect to the left, ventral aspect to the right. Scale bar $=100 \mu \mathrm{m}$.

P. parthenogeneticum resembles $P$. (P.) trigonus Townes (in Maschwitz \& Cook, 2000), but it is separable by abdominal tergites without white patches, superior volsella not large with 4 inner setae and lateral seta absent.

Within the family Chironomidae, 24 formal described species have been recorded from many types of phytotelmata (Siri and Donato 2014; Paul et al. 2014; Dantas and Hamada 2017; Siri and Donato 2018), and from these species, 6 belong to the genus Polypedilum. One of them is $P$. (P.) solimoes that was treated above. The species $P$. pedipalpus (Picado) is known from its original description as larva, pupa and female and is not possible to be assigned to any of the subgenera. From the remaining species, two of them belong 
to the subgenus Polypedilum. The presence of spotted wings and the superior volsella with 3 inner setae in the male and the spinules on conjunctive V-VI, lacking of median patches of shagreen in tergite III, fine and weak shagreen on tergites IV and V, and anal comb with several spines of the pupa separates the species Polypedilum (P.) panacu Mendes et al. 2011 from $P$. (P.) parthenogeneticum. The other species is Polypedilum (Polypedilum) kaingangi, described by Pinho et al. (2013). This species is clearly differentiated from $P$. $(P$.) parthenogeneticum by having a highly setose clypeus (63-78 to 22 in $P$. (P.) parthenogeneticum) and the superior volsella has 2 inner setae in the male; the pupa with fine and weak shagreen on tergites III, IV and $\mathrm{V}$, and anal comb with several spines.

Recently the Neotropical fauna of the genus Polypedilum was increased by Shimabukuro et al. 2019. In that study, the authors described two species in the subgenus Polypedilum. The species

Polypedilum $(P$. ) caete differs from $P$. $(P$.) parthenogeneticum by the possession of a long lateral seta in the superior volsella; 4-6 setae arranged in a row on inferior volsella; presence of weak marking on wings and RM distinctly darkened; and scale of fore tibia apically truncated. The other species is Polypedilum (P.) aymbere that is separable from $P$. $(P$.) parthenogeneticum by the anal point small and club-shaped; projection of superior volsella proximally enlarged, presenting a lateral seta in the middle of the projection and with 3 inner setae; and inferior volsella bearing a apical seta and 3-4 preapical.

\section{Acknowledgements}

This paper is supported by CONICET and UNLP project 11/N785.

\section{References}

Bidawid-Kafka, N. and Fittkau, E.J. 1995. Zur Kenntnis der neotropischen Arten der Gattung Polypedilum Kieffer, 1912. Teil 1. (Diptera, Chironomidae). - Entomofauna 16 (27): 465-534.

Bidawid-Kafka, N. 1996. Zur Kenntnis der neotropischen Arten der Gattung Polypedilum Kieffer, 1912. Teil 2. (Diptera, Chironomidae). - Entomofauna 17 (11): 165-240.

Cabrera, A.L. and Willink, A. 1973. Biogeografía de América Latina. Monografía 13, Serie de Biología, OEA, Washington, D.C. 120 p.

Cranston, P.S., Dillon, M.E., Pinder, L.C.V., and Reiss, F. 1989. The adult males of Chironominae (Diptera, Chironomidae) of the Holarctic region - keys and diagnoses, - Entomologica Scandinavica Supplement 34: 353-502.

Cranston, P.S., Martin, J. and Spies, M. 2016. Cryptic species in the nuisance midge Polypedilum nubifer (Skuse (Diptera: Chironomidae) and the status of Tripedilum Kieffer. - Zootaxa 4079 (4): 429-447. https://doi.org/10.11646/zootaxa.4079.4.3

Dantas, G.P.S., and Hamada, N. 2017. Monopelopia Fittkau, 1962 (Diptera: Chironomidae) from the Neotropical region: five new species, new records and updated keys. - Zootaxa 4358 (1): 45-78. DOI: https://doi.org/10.11646/zootaxa.4358.1.2

Donato, M., and Paggi, A.C. 2008. Polypedilum parthenogeneticum (Diptera: Chironomidae): A new parthenogenetic species from Eryngium L. (Apiaceae) phytotelmata. - Aquatic Insects 30 (1), 51-60. DOI: http://dx.doi.org/10.1080/01650420701829633

Maschwitz, D., and Cook, E.F. 2000. Revision of the Nearctic species of the genus Polypedilum Kieffer (Diptera: Chironomidae) in the subgenera P. (Polypedilum) Kieffer and P. (Uresipedilum) Oyewo and Saether. - Bulletin of the Ohio Biological Survey, New Series 12 (3): 1-135.

Mendes, H.F., Andersen, T., and Jocqué, M. 2011. A new species of Polypedilum Kieffer from bromeliads in Parque Nacional Cusuco, Honduras (Chironomidae: Chironominae). - Zootaxa 3062: 46-54. DOI: http://dx.doi.org/10.11646/zootaxa3062.1.5

Paul, N., Hazra, N. and Mazumdar, A. 2014. Monopelopia mongpuense sp. n., a phytotelmata midge from sub-Himalayan region of India (Diptera: Chironomidae: Tanypodinae). - Zootaxa 3802 (1): 122-130. DOI: http://dx.doi.org/10.11646/zootaxa.3802.1.10

Pinho, L.C., Mendes, H.F., Andersen, T. and Marcondes, C.B. 2013. Bromelicolous Polypedilum Kieffer from South Brazil (Diptera: Chironomidae). - Zootaxa 3652: 569-581. DOI: http://dx.doi.org/10.11646/ zootaxa.3652.5.6 
Sæther, O.A., Andersen, T., Pinho, L.C. and Mendes, H.F. 2010. The problems with Polypedilum Kieffer (Diptera: Chironomidae), with the description of Probolum subgen. n. - Zootaxa 36: 1-36. DOI: http:// dx.doi.org/10.11646/zootaxa.2497.1.1

Shimabukuro, E.M., Trivinho-Strixino, S. and Lamas, C.J.E. 2019. New Polypedilum Kieffer (Diptera: Chironomidae) from mountains of the Atlantic Forest, Brazil. - Zootaxa 4612 (4): 518-532. DOI: https://doi.org/10.11646/zootaxa.4612.4.4

Siri, A., and Donato, M. 2014. Monopelopia caraguata (Chironomidae: Tanypodinae: Pentaneurini) and Phytotelmatocladius delarosai (Chironomidae: Orthocladiinae): Two phytotelmatous chironomids distributed from Florida to Argentina. - Florida Entomologist 97 (3): 1226-1231. DOI: https://doi. org/10.1653/024.097.0330

Siri, A., and Donato, M. 2018. Parapentaneura (Diptera: Chironomidae: Tanypodinae) breeding in phytotelmata and the conflictive phylogenetic relationship with Pentaneura and Hudsonimyia. - Zoologischer Anzeiger 277: 65-74. DOI: http://dx.doi.org/10.1016/j.jcz.2018.09.002

Vandel, A. 1928. La parthénogénèse geographique. Contribution à l'étude biologique et cytologique de la parthénogénèse naturelle. - Bulletin Biologique de France et Belge 62: 164-281.

Vårdal, H., Bjørlo, A. and Sæther, O.A. 2002. Afrotropical Polypedilum subgenus Tripodura, with a review of the subgenus (Diptera: Chironomidae). - Zoologica Scripta 31 (4): 331-402. DOI: https://doi. org/10.1046/j.1463-6409.2002.00096.x

Yamamoto, N. and Yamamoto, M. 2016. The taxonomic implication of frontal tubercles in Polypedilum subgenera diagnoses, with re-description of Polypedilum isigabeceum Sasa \& Suzuki (Diptera, Chironomidae). - Zootaxa 4193 (1): 189-194. DOI: http://dx.doi.org/10.11646/zootaxa.4193.1.11

Article submitted 29. August 2019, accepted by Barbara Hayford 27. September 2019, published 11. October 2019. 